\title{
Emergent behavior in a coupled economic and coastline model for beach nourishment
}

\author{
E. D. Lazarus ${ }^{1}$, D. E. McNamara ${ }^{2}$, M. D. Smith ${ }^{3}$, S. Gopalakrishnan ${ }^{4}$, and A. B. Murray ${ }^{5}$ \\ ${ }^{1}$ School of Earth and Ocean Sciences, Cardiff University, Main Building, Park Place, Cardiff CF10 3AT, UK \\ ${ }^{2}$ Department of Physics and Physical Oceanography, Center for Marine Science, University of North Carolina-Wilmington, \\ 601 South College Road, Wilmington, NC 28403, USA \\ ${ }^{3}$ Nicholas School of the Environment, Dept. of Economics, Duke University, P.O. Box 90328, Durham, NC 27708, USA \\ ${ }^{4}$ Department of Agricultural, Environmental and Development Economics, The Ohio State University, 2120 Fyffe Road, \\ Columbus, OH 43210, USA \\ ${ }^{5}$ Division of Earth and Ocean Sciences, Nicholas School of the Environment, Center for Nonlinear and Complex Systems, \\ Duke University, 103 Old Chemistry Building, P.O. Box 90227, Durham, NC 27708, USA
}

Received: 6 July 2011 - Revised: 24 October 2011 - Accepted: 2 December 2011 - Published: 15 December 2011

\begin{abstract}
Developed coastal areas often exhibit a strong systemic coupling between shoreline dynamics and economic dynamics. "Beach nourishment", a common erosion-control practice, involves mechanically depositing sediment from outside the local littoral system onto an actively eroding shoreline to alter shoreline morphology. Natural sedimenttransport processes quickly rework the newly engineered beach, causing further changes to the shoreline that in turn affect subsequent beach-nourishment decisions. To the limited extent that this landscape/economic coupling has been considered, evidence suggests that towns tend to employ spatially myopic economic strategies under which individual towns make isolated decisions that do not account for their neighbors. What happens when an optimization strategy that explicitly ignores spatial interactions is incorporated into a physical model that is spatially dynamic? The longterm attractor that develops for the coupled system (the state and behavior to which the system evolves over time) is unclear. We link an economic model, in which town-manager agents choose economically optimal beach-nourishment intervals according to past observations of their immediate shoreline, to a simplified coastal-dynamics model that includes alongshore sediment transport and background erosion (e.g. from sea-level rise). Simulations suggest that feedbacks between these human and natural coastal processes can
\end{abstract}

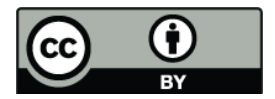

Correspondence to: E. D. Lazarus (edlazarus@gmail.com) generate emergent behaviors. When alongshore sediment transport and spatially myopic nourishment decisions are coupled, increases in the rate of sea-level rise can destabilize economically optimal nourishment practices into a regime characterized by the emergence of chaotic shoreline evolution.

\section{Introduction}

Along sandy shorelines where erosion threatens waterfront property and infrastructure, beach nourishment is a commonly employed land-management strategy and engineering practice. Nourishment involves taking sand from a source site and depositing it onto an eroded beach, as a so-called "soft" alternative to permanent rock or concrete emplacements such as groynes and seawalls; groynes corral sand by locally obstructing sediment transport, while seawalls armor the shoreline outright (Pilkey and Wright, 1988). In the US, beach nourishment has cost more than $\$ 2.5$ billion since 1950 (NOAA, 2006). The number and cost of nourishment projects have increased markedly in the last decade - a trend that is likely to continue given estimates for economic impacts of sea-level rise (NOAA, 2006; Smith et al., 2009; Titus et al., 1991; Sugiyama, 2007).

Beach nourishment tends to occur where there is real estate development along a dynamic sandy coastline. If natural fluctuations in shoreline position are predominantly erosive

Published by Copernicus Publications on behalf of the European Geosciences Union and the American Geophysical Union. 
and impinge upon development, town managers may opt for beach nourishment as a mitigation strategy and artificially build out the beach to a predetermined maximum width. But a beach-nourishment project is rarely an isolated event. Wave action and gravity gradually rework and redistribute the engineered beach until erosion again poses a threat to waterfront development, setting in motion a repetitive cycle of erosion, impingement, and nourishment. If local coastal erosion is persistent, a town that nourishes its beach will typically need to nourish again within a few years (NRC, 1995; PSDS, 2010). Long-term beach-nourishment projects incorporate 50-year timetables to account for periodic re-nourishment maintenance (NRC, 1995; Pilkey and Dixon, 1996).

Beach nourishment is thus the linking action that powers a coupled human-landscape system wherein beach dynamics include interactions between the economics of coastal development and the physical processes of shoreline change. The economic motivation behind beach nourishment is that a beach can be viewed as natural capital. A wide beach, which affords storm protection to oceanfront property and provides recreational value to tourists, is worth money. Tourismrelated businesses and property owners who risk erosion or flooding are direct beneficiaries, but so is the town to which the beach belongs, through real-estate values, hotel occupancy, and sales taxes. The value of amenities provided by a wide beach is capitalized into coastal property values (Edwards and Gable, 1991; Gopalakrishnan et al., 2011; Kreisel et al., 2005; Landry et al., 2003; Parsons and Powell, 2001; Pompe and Rinehart, 1995) and influences shoreline stabilization strategies. A recent economic model of beach nourishment incorporates the value of natural capital (based on previous empirical studies) into a parameter for beach width, and then employs this encapsulation in a cost-benefit analysis that optimizes the frequency of beach nourishment as a function of erosion rate, property value, project costs, and financial discounting (Smith et al., 2009). The result is the economically optimal interval over which a town should nourish its beach to maximize its net benefits through infinite time, assuming physical and economic parameters remain constant. The theoretical model predictions are consistent with empirical data on nourishment intervals in North Carolina (Gopalakrishnan et al., 2011). The optimization model, however, is spatially myopic, designed for a town that acts without considering how its neighbors manage their beaches. This economic myopia is a real phenomenon and continues to be standard practice on managed coastlines where beach nourishment is commonplace (PSDS, 2010; Psuty and Ofiara, 2002).

One investigative approach to coupled human and natural systems rests on the premise that to better understand a particular physical or ecological system, the dynamics of human interactions require consideration (e.g. Parker et al., 2003; Wilson, 2006; Werner and McNamara, 2007). For this work, we adopt the inverse perspective: Fresh insight into human-driven landscape patterns needs to account for certain dynamic physical processes. What happens when a spatially isolated but widely practiced landscape-management decision operates in a spatially extended, physically integrated environment? If the economic optimization framework for beach nourishment from Smith et al. (2009) is placed in a spatially extended domain (a string of neighboring towns, each with its own coastal manager) influenced by simple physical processes (the lateral redistribution of sand between neighboring towns by alongshore sediment transport), how does the system behave through time?

We present results from an exploratory numerical model in which manager agents for a string of neighboring coastal towns choose economically optimal beach-nourishment intervals according to past observations of shoreline change at their beaches. Simplified coastal dynamics for the physical setting are implemented as (1) alongshore sediment transport, and (2) background erosion that represents, for example, the expected results of sea-level rise and consequent cross-shore sediment redistribution (e.g. Wolinsky and Murray, 2009). Theoretical and empirical precedent for this approach is a spatially-extended, coupled model examining the linked dynamics of resort development and beach nourishment on barrier islands, like those along the US Mid-Atlantic Seaboard (McNamara and Werner, 2008a, 2008b). Examples of other resource-optimization analyses in spatially-extended settings can be found in contexts of land use (e.g. Irwin and Bockstael, 2002; Bell and Irwin, 2002; Parker and Munroe, 2007; Albers et al., 2008), forestry (e.g. Swallow et al., 1997), and fisheries (e.g. Sanchirico and Wilen, 2005; Wilson et al., 2007).

We find that when lateral diffusion of sediment is endogenous in the system, such that one town's beach changes at a rate that depends on the relative positions of other towns' beaches, emergent patterns can arise in shoreline behavior over time. Furthermore, increases in the rate of sea-level rise can destabilize what appeared to be economically optimal nourishment practices into a chaotic regime. If spatially myopic economic optimization leads to unanticipated outcomes, emergent behaviors of the coupled spatial system may invalidate the assumptions underpinning the optimization framework. In essence, towns make decisions that impact neighboring towns in ways that result in emergent, long-time-scale dynamics different from those they presumed would occur. This process raises questions about how towns actually behave when spatial myopia feeds back on their own (and not just their neighbors') future prospects. 


\section{Methods}

\subsection{Model}

\subsubsection{Economically driven management of beach width}

Beach nourishment decisions for a given town are made by manager agents who act according to the capital accumulation model for beach nourishment in Smith et al. (2009). Manager agents determine the nourishment interval $(\tau)$ that maximizes the net benefits (NB) derived from beach nourishment in their respective towns:

$\mathrm{NB}(\tau)=B(\tau)-C(\tau)$

where $B(\tau)$ is the benefits function and $C(\tau)$ is the cost of a nourishment project. The cost function includes the variable cost of a project, which is a function of the amount of sand required to build the beach out to a chosen "maximum" cross-shore width $\left(x_{0}\right)$, and the fixed cost of a project $(c)$, which includes assessment, permitting, and equipment for dredging and spreading:

$C(\tau)=c+\phi\left(x_{0}-x(\tau)\right)$,

where $\varphi$ is the cost of sand per cross-shore meter of beach added. Note that $x_{0}$ can be specified exogenously or chosen endogenously in the Smith et al. (2009) framework. The benefits function,

$B(\tau)=\int_{0}^{\tau} e^{-\delta t} \delta \alpha\left[c(\tau)^{\beta}\right] d t$

incorporates a discount rate $(\delta)$, the base value (the value of all attributes except beach width) of beachfront property $(\alpha)$, and the hedonic price of beach width $(\beta)$. A hedonic pricing model breaks down the price of a residential (or commercial) property as a function of property characteristics (e.g. number of rooms, lot size, year built), neighborhood characteristics (e.g. school district, crime rates), and environmental attributes (beach width) (Rosen, 1974). The discount rate $(\delta)$ is also assumed to be the capitalization rate to convert beach value into amenity flows.

Manager agents in the model assess cross-shore beachwidth change in their towns according to two principal parameters: a linear erosion rate $(\gamma)$, and an exponential erosion rate $(\theta)$,

$x(t)=(1-\mu) x_{0}+\mu e^{-\theta t} x_{0}-\gamma t$,

where $\mu(0 \leq \mu \leq 1)$ is the fraction of the maximum beach width that erodes exponentially. The exponential term captures the approximate time scale of a nourishment event (Dean, 2002; Smith et al., 2009) such that erosion is highest immediately after nourishment, consistent with the way nourished beaches tend to relax from an initially steep crossshore profile into a wave-carved, equilibrium profile (Dean and Dalrymple, 2002). The remainder of the beach width $(1-\mu)$ erodes linearly at rate $\gamma$. Linear erosion could represent a consequence of sea-level rise. Note that $t$ in Eqs. (3) and (4) represents time since the last nourishment event, not total time, and therefore is periodically reset. Differentiating Eq. (4) with respect to time yields the manager agents' state equation for beach width:

$\dot{x}(t)=-\mu \theta e^{\theta t} x_{0}-\gamma$.

As the widths of town beaches change, manager agents try to determine how often to nourish, on an interval that maximizes their net benefits through time. For a total present value $(v)$

$$
\begin{aligned}
v\left(\tau_{1}, \tau_{2}, \tau_{3}, \ldots \tau_{n}\right)= & \mathrm{NB}\left(\tau_{1}\right)+e^{-\delta \theta_{1}} \mathrm{NB}\left(\tau_{2}\right)+e^{\delta \tau_{2}} \mathrm{NB}\left(\tau_{e}\right) \\
& +\ldots+e^{-\delta \tau_{n}} \mathrm{NB}\left(\tau_{n}\right),
\end{aligned}
$$

where each $\left(\tau_{i}\right)$ represents total time from when planning begins. Assuming erosion dynamics remain constant, the value of an infinite nourishment rotation can be written as an infinite geometric series,

$v(\tau)=\sum_{k=0}^{\infty} e^{-\delta k \tau} \mathrm{NB}(\tau)=\mathrm{NB}(\tau) /\left(1-e^{\delta \tau}\right)$,

where $\tau$ is the length of time since the previous nourishment event. Manager agents therefore choose an optimal $\tau$ that solves the maximization problem:

$\max v(\tau)=(B(\tau)-C(\tau)) /\left(1-e^{\delta t}\right)$.

"Optimal" in this case is from the perspective of a given manager in a given location, responding to the particular behavior of that town's beach, and it ignores the ecological consequences of nourishment.

Figure 1 shows the parameter space for the optimal nourishment interval $(\tau)$ as a function of linear $(\gamma)$ and exponential $(\theta)$ rates of erosion. The contour shape is informed by the economic parameters in Eqs. (2) and (3), which here we hold constant in keeping with Smith et al. (2009): $\alpha=200$, $\beta=0.25, \delta=0.06, c=10$, and $\phi=1$. Manager agents in the model use the parameter space plotted in Fig. 1 to calculate their respective optimal nourishment intervals on the basis of changes they observe in their beach widths, or their linear $(\gamma)$ and exponential $(\theta)$ erosion rates. When the time elapsed since the previous nourishment is equal to a town's interval $\tau$, the town nourishes its beach out to the maximum width $\left(x_{0}\right)$. The model assumes that towns round $\tau$ to the nearest integer (they do not nourish mid-year).

\subsubsection{Shoreline dynamics}

We simulate a highly simplified oceanfront landscape by parceling a linear shoreline into a series of neighboring towns, each overseen by its own manager agent. We assume towns have equal alongshore extents of $y=10 \mathrm{~km}$ and periodic boundary conditions. The key amendment we make to 


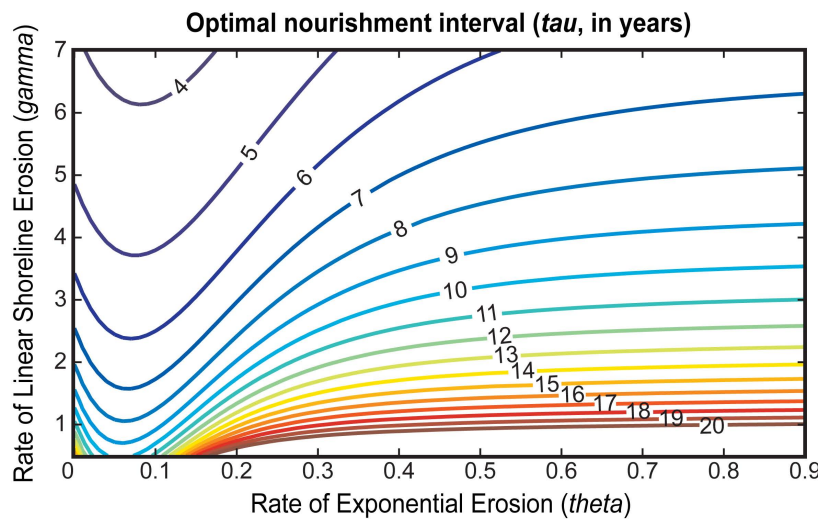

Fig. 1. Parameter space of optimal nourishment interval $(\tau)$ plotted as a function of linear erosion rate $\left(\gamma_{\mathrm{r}}\right)$ and the exponential relaxation rate of the cross-shore beach profile $\left(\theta_{\mathrm{r}}\right)$.

the physical behavior of a given beach within the spatially extended shoreline is the addition of a diffusion term due to alongshore sediment transport into the state equation for beach width, Eq. (5),

$\dot{x}(t)=K \frac{\partial^{2} x}{\partial y^{2}}-\mu \theta e^{\theta t} x_{0}-\gamma$

where $K$ is a diffusivity coefficient. Our treatment of $K$ follows an argument for wave-driven diffusivity detailed in Ashton and Murray (2006a, b), and represents the sedimenttransport effects of shore-incident waves approaching predominantly from low angles relative to the shoreline (approximately $>-45^{\circ}$ and $<45^{\circ}$ from shore-normal). For the results presented here, we use $K=30000 \mathrm{~m} \mathrm{~s}^{-1}$.

Introducing diffusion from alongshore sediment transport to the model landscape makes it necessary to distinguish between the "real" erosion rate at a given beach, determined by Eq. (9), and the "perceived" linear and exponential erosion rates that a manager agent observes. A manager agent measures linear and exponential erosion rates by fitting a curve to a time series of town beach widths; the time series for curve fitting extends from the town's most recent nourishment event to the present. In the case of a single town (or equivalently, if the entire domain of towns acts in unison), the plan-view shoreline changes as a uniform block; with no plan-view perturbations on which to act, $\partial^{2} x / \partial y^{2}=0$. The erosion rates "perceived" by the manager agents, labeled as $\gamma_{\mathrm{p}}$ and $\theta_{\mathrm{p}}$,

$\dot{x}(t)-\mu \theta_{\mathrm{p}} e^{-\theta_{\mathrm{p}} t} x_{0}-\gamma_{\mathrm{p}}$

are the same as the "real" (operator-fixed) erosion rates, $\gamma_{\mathrm{r}}$ and $\theta_{\mathrm{r}}$,

$\dot{x}(t)=K \frac{\partial^{2} x}{\partial y^{2}}-\mu \theta_{\mathrm{r}} e^{-\theta_{\mathrm{r}} t} x_{0}-\gamma_{\mathrm{r}}$

However, if one town in the domain nourishes its beach out of turn, perturbing the plan-view shoreline with a sharp seaward-projecting bump, Eq. (11) demonstrates that diffusion from alongshore sediment transport acting on the perturbation will give rise to an erosion rate at that beach that is greater than the fixed rate. Sand from the nourished beach is redistributed alongshore to neighboring towns whose beaches consequently erode less rapidly than the fixed rate.

Active alongshore sediment transport therefore guarantees that towns gain or lose sand as a result of their neighbors' nourishment decisions. However, because manager agents in this model operate independently of each other (one manager agent does not know when another plans to nourish) and calculate their optimal nourishment intervals according to the spatially isolated relationship in Eq. (10), they have to adjust their perceived linear $\left(\gamma_{\mathrm{p}}\right)$ and exponential $\left(\theta_{\mathrm{p}}\right)$ erosion rates to reconcile the neighbor-influenced beach-width changes they observe. Such adjustments can result in manager agents calculating different optimal nourishment intervals even in the absence of economic heterogeneity, changing their positions in the parameter space shown in Fig. 1. That is, otherwise economically identical towns could choose different nourishment intervals solely as artifacts of past timings of neighboring nourishments.

\subsection{Chaotic time-series analysis}

We utilize a nonlinear time series forecasting technique to evaluate the degree of nonlinearity in a time series of modeled beach width, $s_{n}$ (Abarbanel, 1986). Specifically, a time series of beach width from a single town in the modeled coastline is split into two halves. One half is deemed the "training set" and the other half the "predicting set". The training set is embedded in an $m$-dimensional phase space with vector positions, $\boldsymbol{X}_{n}$, in the phase space given by

$\boldsymbol{X}_{n}=\left[w_{n}, w_{n+l}, w_{n+2 l}, \ldots, w_{n+(d-1) l}\right]$,

where $l$ is a time lag and $d$ is the embedding dimension. The value of the time lag can be found by finding the first minimum in the average mutual information function, and the embedding dimension can be found by using the false nearneighbors test (Abarbanel, 1986).

A forecast is made by first choosing a vector from the prediction set and placing it in the $m$-dimensional phase space. A prediction from this vector looking $h$ steps forward in time is made using the autoregressive model (Casdagli, 1989)

$w_{n+h}=a_{o}+\sum_{j=0}^{j=d-1} a_{j+1} w_{n-j l}$.

Coefficients for the autoregressive model are found using points from the training set that, in the phase space, are near the point from which the predictions are made. The degree of nonlinearity in the time series is determined by expressing the accuracy of the prediction as a function of the variation in the number of training-set near-neighbors used to train the 

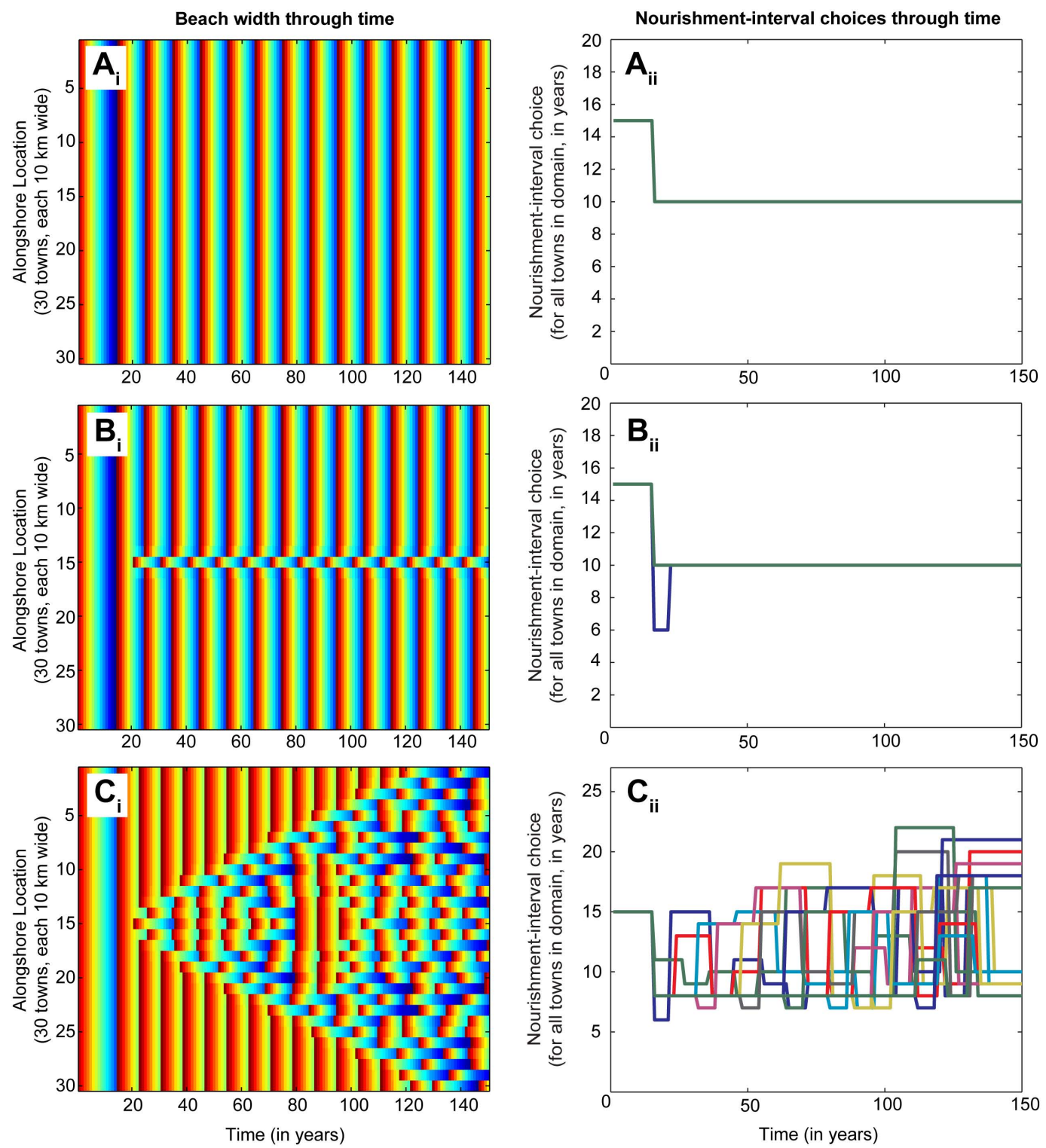

Fig. 2. Beach width (i) and nourishment-interval choice (ii) plotted through time for three example scenarios. Color in (i) indicates beach width, wide (reds) to narrow (blues). In (a), $\tau$ is homogenous over the whole domain. The effect of forcing the middle town to nourish out of turn differs depending on external forcing conditions: (b) shows beach width and $\tau$ through time for $\gamma_{\mathrm{r}}=0.5 \mathrm{~m} \mathrm{yr}^{-1}$; (c) shows the onset of instability if background erosion is increased to $\gamma_{\mathrm{r}}=1.5 \mathrm{~m} \mathrm{yr}^{-1}$.

prediction model (Casdagli, 1989; Sugihara and May, 1990). For example, a noisy, linear time series would yield the highest prediction accuracy when using all points in the phase space for training. If prediction accuracy is highest for a small to intermediate number of near neighbors used to train the data set, then this suggests localization of the phase space behavior and that the time series is nonlinear.

\section{Results}

In the simplest case, given a uniform plan-view shoreline with $\gamma_{\mathrm{r}}=0.5 \mathrm{~m} \mathrm{yr}^{-1}$ and $\theta_{\mathrm{r}}=0.05$, manager agents all calculate correctly $\gamma_{\mathrm{p}}=\gamma_{\mathrm{r}}$ and $\theta_{\mathrm{p}}=\theta_{\mathrm{r}}$ to find a nourishment interval of $\tau=10 \mathrm{yr}$ (Fig. 2a), which is the corresponding optimal nourishment solution prescribed by Fig. 1. Because the uniform shoreline nullifies diffusion, the domain operates according to the imposed $\gamma_{\mathrm{r}}, \theta_{\mathrm{r}}$, and corresponding $\tau$, demonstrating a steady state for the coupled system in the absence of spatial interactions between town beaches. 
Figure $2 \mathrm{~b}$ shows the spatiotemporal pattern that results from forcing one town in the domain (here, the middle town) to nourish initially out of sync with its neighbors, so that diffusion acts on the resulting plan-view shoreline perturbation. As in Fig. $2 \mathrm{a}, \gamma_{\mathrm{r}}=0.5 \mathrm{~m} \mathrm{yr}^{-1}$ and $\theta_{\mathrm{r}}=0.05$, and even though they do not all nourish in unison, manager agents still find the steady-state interval of $\tau=10 \mathrm{yr}$. When the middle town nourishes ahead of its neighbors, the neighbors benefit from the receipt of "free" sand via diffusion; when other towns nourish but the middle town lags, the middle town receives free sand diffused from its neighbors. The effect of diffusion on beach widths in Fig. $2 b$ is not so great that manager agents calculate incorrectly their rates of linear and exponential erosion. Having perturbed the coupled-system steady state without changing the forcing, we find the steady state of $\tau=10 \mathrm{yr}$ behaves like an attractor. To see how the attractor evolves, we probe the response of the steady state to changes in the external forcing - for this system, by incrementally increasing sea-level rise (represented by the rate of linear erosion, $\gamma_{\mathrm{r}}$ ).

Figure $2 \mathrm{c}$ shows the evolution of beach widths through time when linear erosion is increased to $\gamma_{\mathrm{r}}=1.5 \mathrm{~m} \mathrm{yr}^{-1}$ (exponential erosion remains fixed at $\left.\theta_{\mathrm{r}}=0.05\right)$. The economic net-benefit analysis in Smith et al. (2009) shows that towns will nourish more frequently (choose shorter optimal nourishment intervals) as linear erosion increases (Fig. 1). This is reflected in Fig. 2c by the towns at the margins of the domain, where nourishment events occur at closer intervals than under the lower erosion rates imposed in Fig. 2b. With linear erosion increased in Fig. 2c, contrary to the attractor behavior in Fig. 2b, the asynchronous initial nourishment by the middle town now affects neighboring towns in a way that triggers a dynamic instability that propagates across the domain. (Reducing the step size in the numerical scheme (not shown) verifies that the pattern in Fig. $2 \mathrm{c}$ is not the result of a numerical instability.) Once the middle town nourishes first, the instability propagates as follows: (1) sand from the middle town diffuses to its neighbors; (2) manager agents in those neighboring towns register a slower erosion rate, prompting them to amend their calculations of $\gamma_{\mathrm{p}}$ and $\theta_{\mathrm{p}}$ to choose a longer optimal nourishment interval $(\tau)$; (3) the choice of a longer interval $(\tau)$ forces those towns out of sync with their neighbors to the north and south, respectively. Beginning with manager agents' misinterpretation of diffusion-altered erosion rates and consequent selection of a non-optimal, longer nourishment interval, this desynchronization spreads laterally as an edge effect from the initial perturbation.

Why does the instability not occur in the Fig. 2b scenario, where diffusion is also active? The forced linear erosion rate $\left(\gamma_{\mathrm{r}}\right)$ plays an important role, as does the timing of when, in a given nourishment period, a delivery of unexpected sand arrives. A manager agent calculates $\gamma_{\mathrm{p}}$ and $\theta_{\mathrm{p}}$ by curvefitting the town's beach-width data since its most recent nourishment event. The instability is in part a function of how many previous beach-width data points manager agents have at their disposal when sand diffuses in from a neighboring

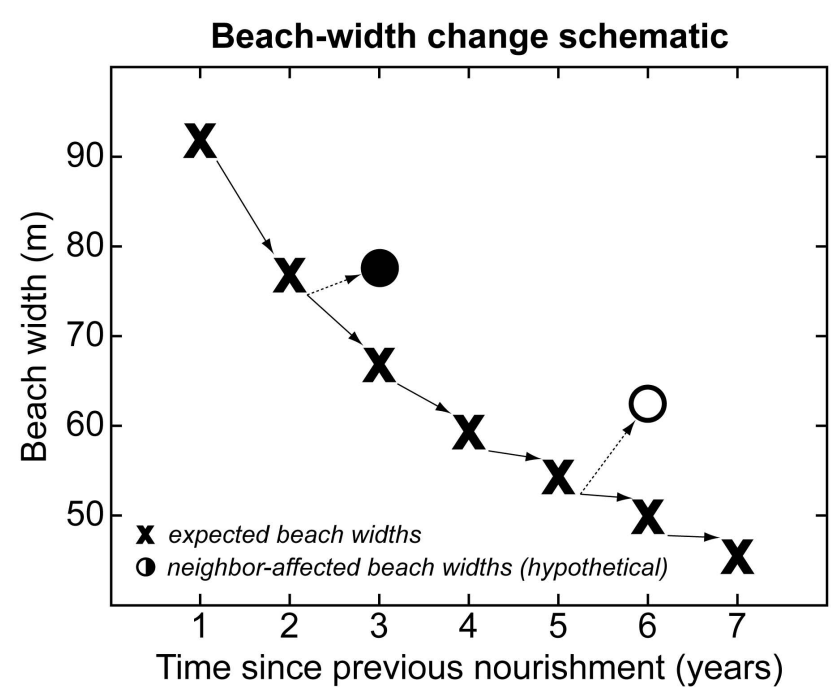

Fig. 3. Schematic of beach-width through time for a given model town. If a delivery of diffused sand arrives late in the erosion cycle (open circle), where linear erosion predominates, manager agents decrease $\gamma_{p}$. Agents interpret an early-cycle delivery of sand (closed circle) as a change in the exponential erosion rate, prompting them to increase $\theta_{\mathrm{p}}$ and decrease $\gamma_{\mathrm{p}}$.

nourishment project. Figure 3 illustrates the dynamical difference between the scenarios in Fig. $2 b$ and c. If the attractor for the coupled system in the absence of spatial interactions between town beaches is a long nourishment interval and the unexpected sand arrives relatively late in the nourishment period (e.g. Fig. 2b), then a manager agent has enough information to differentiate between exponential and linear erosion in the beach-width curve, and interprets the change as a small decrease in $\gamma_{\mathrm{p}}$ (the open circle in Fig. 3). With many data points informing the interpolation, a late-stage adjustment in the linear erosion rate has a negligible influence on the agent's calculated nourishment interval. The town stays on the attractor. However, if the "optimal" nourishment interval is shorter (e.g. Fig. 2c) and sand diffused from neighboring towns arrives early in a nourishment cycle (the closed circle in Fig. 3), a manager agent attributes the new the beach width primarily to a change in the rate of exponential erosion. The agent increases $\theta_{\mathrm{p}}$ and decreases $\gamma_{\mathrm{p}}$, and calculates a longer - erroneous - interval $\tau$.

Manager calculations are not sensitive simply to the timing of an unexpected delivery within a nourishment cycle the linear erosion rate is a key variable. When erosion rates are low (Fig. 2b), towns stay on the attractor even if unexpected sand arrives early in the nourishment cycle. The relative offset in beach widths between neighbors is small under these conditions, and diffusion has only a minor influence when offsets are small. The less influence diffusion has on beach-width change, the more accurate a manager agent's calculations are. When erosion rates are high, the relative 


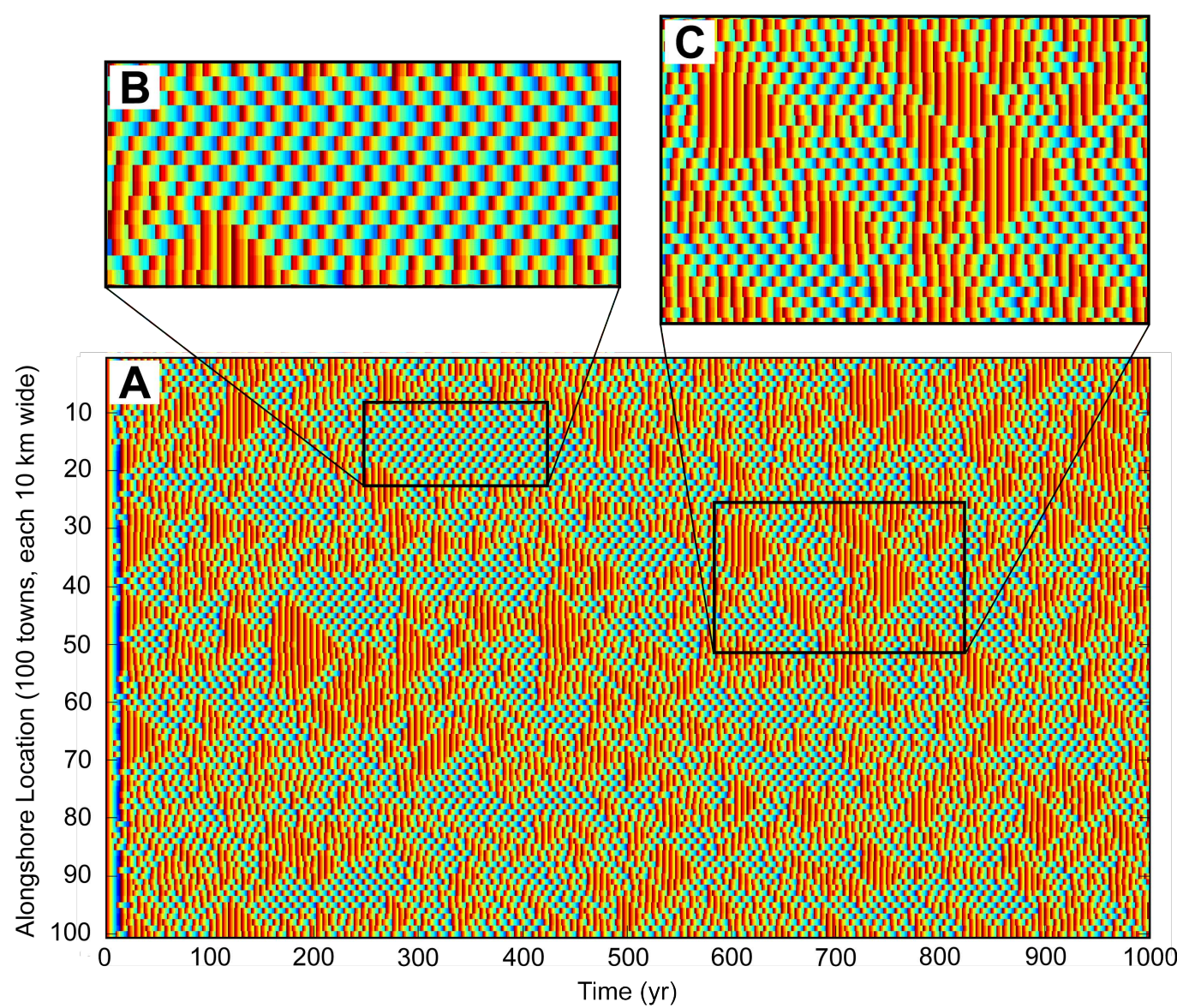

Fig. 4. (a) Beach width through time for 100 towns over $1000 \mathrm{yr}$ for $\gamma_{\mathrm{r}}=3.5 \mathrm{~m} \mathrm{yr}^{-1}$. Insets highlight two quasi-stable states: (b) checkerboard patterning; and (c) dissipative grouping.

offset between nourishing and non-nourishing towns is increased (Fig. 2c): The maximum width of a nourished beach $\left(x_{0}\right)$ is unchanged, but towns are losing more sand annually to erosion. Large offsets between neighboring towns intensifies diffusion, tending to make manager agents miscalculate their optimal nourishment intervals.

The same dynamic that propagates the marginal edgeeffect also prevents groups of towns in the domain interior from restabilizing their nourishment patterns. Note in Fig. 2c that the middle town, once its immediate neighbors nourish and diffuse (Year 26), perceives a slower erosion rate and chooses a $\tau$ so long that its immediate neighbors nourish again (Year 35) before the middle town reaches the end of its interval (Year 36). As a result of this localized stutterstepping, the middle town and a growing line of local neighbors nourish almost in unison during Years 35-50, shortening their nourishment intervals in closer correspondence to the higher, "real" erosion rate. However, the partially reformed line triggers the edge effect at both ends. By Year 70, the partially reformed line has narrowed and broken up. Though a new line forms again briefly between Years 80-90, by
Year 100 that line too is fragmented into a checkerboard pattern, and by Year 120 the initial instability has propagated across the entire domain.

Once triggered, the instability in Fig. 2c perturbs the coupled system to a new attractor that switches unpredictably between two states - one characterized by strings of towns nourishing frequently and in unison, and the other by towns nourishing over long cycles out of phase with their neighbors (Fig. 4). For erosion rates $\gamma_{\mathrm{r}}=1.2-2.2 \mathrm{~m} \mathrm{yr}^{-1}$, nonlinear time series analysis of a given town's beach width through time shows the dynamic of this new attractor is chaotic (Fig. 5). A nonlinear time series forecast was produced using a lag of $l=20 \mathrm{yr}$ (the first minimum in the average mutual information) and an embedding dimension of $d=3$ (found from the false near-neighbor test). A mid-range number of nearest neighbors used in time series predictions (Eq. 13) yields the highest prediction accuracy (Fig. 5). The strength of predictability falls off with increasing lag. Both characteristics are expected for a chaotic time series.

A bifurcation diagram of $\tau$ states over a range of $\gamma_{\mathrm{r}}$ values highlights the critical threshold (e.g. Feigenbaum, 1978; 


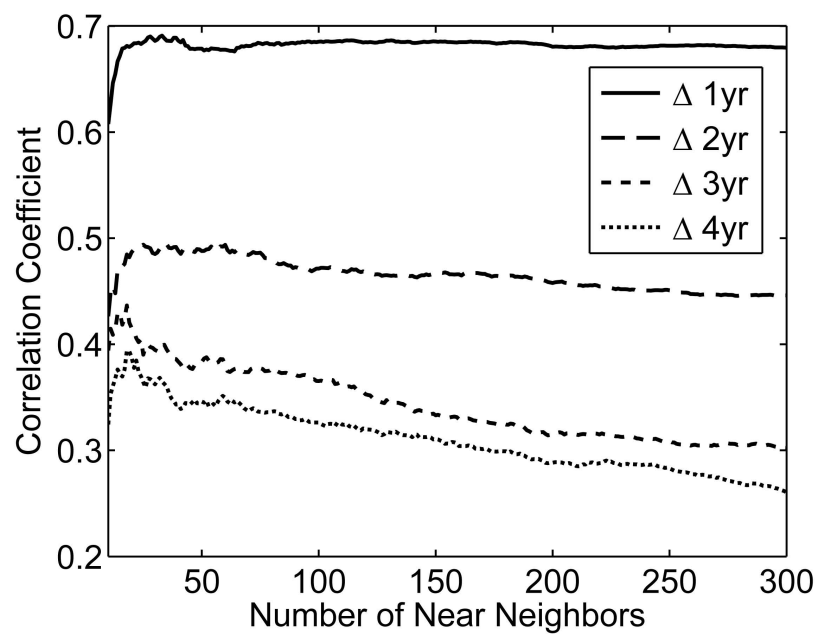

Fig. 5. Correlation between forecasted and observed beach width for town at alongshore location 50 (of 100 towns, with $\gamma_{\mathrm{r}}=$ $1.5 \mathrm{~m} \mathrm{yr}^{-1}$, for a $5000-\mathrm{yr}$ time series), plotted against the number of neighbors used to generate the prediction. Predictions are made at 1 (solid), 2 (large dash), 3 (small dash), and 4 (dotted) years forward in the time series.

Sornette, 2006) into chaotic behavior (Fig. 6). At low values of $\gamma_{\mathrm{r}}\left(\leq 1.1 \mathrm{~m} \mathrm{yr}^{-1}\right)$ towns settle into a nourishment-interval attractor around $\tau=\sim 10 \mathrm{yr}$. But at $\gamma_{\mathrm{r}}=1.2 \mathrm{~m} \mathrm{yr}^{-1}$, the number of $\tau$ states explodes. The more $\tau$ states represented at a given $\gamma_{\mathrm{r}}$ condition, the more erratic the nourishment actions.

Values of $\gamma_{\mathrm{r}} \geq \sim 2.3 \mathrm{~m} \mathrm{yr}^{-1}$ confine towns to nourishment intervals in the NW quadrant of the parameter space (Fig. 1), where $\tau$ contours are flatter and small adjustments in $\gamma_{\mathrm{r}}$ and $\theta_{\mathrm{r}}$ have less effect on a town's choice of $\tau$. Under these more restricted nourishment intervals, the two-state pattern of inphase groups and out-of-phase checkerboards becomes increasingly more regular and densely configured (e.g. Fig. 4). By contrast, a consequence of the steep contour gradient evident in the SW quadrant of Fig. 1 is that relatively small changes in a town's perceived $\gamma_{p}$ and $\theta_{p}$ can result in $\tau$ choices that differ by a factor of 2 or more (Fig. 2c). Under background erosion rates of $\gamma_{\mathrm{r}}=1.2-2.2 \mathrm{~m} \mathrm{yr}^{-1}$, near the chaotic threshold, manager agents choose nourishment intervals from the region of the parameter space where the $\tau$ gradient is steepest (Fig. 1), making their calculations especially sensitive to diffusion-related changes in their beach widths affected by their neighbors (Fig. 2c).

\section{Discussion}

\subsection{Initial conditions}

Instability in the model is not sensitive to initial conditions. For example, it does not matter which towns in the domain nourish first, or precisely when. Initial conditions affect the

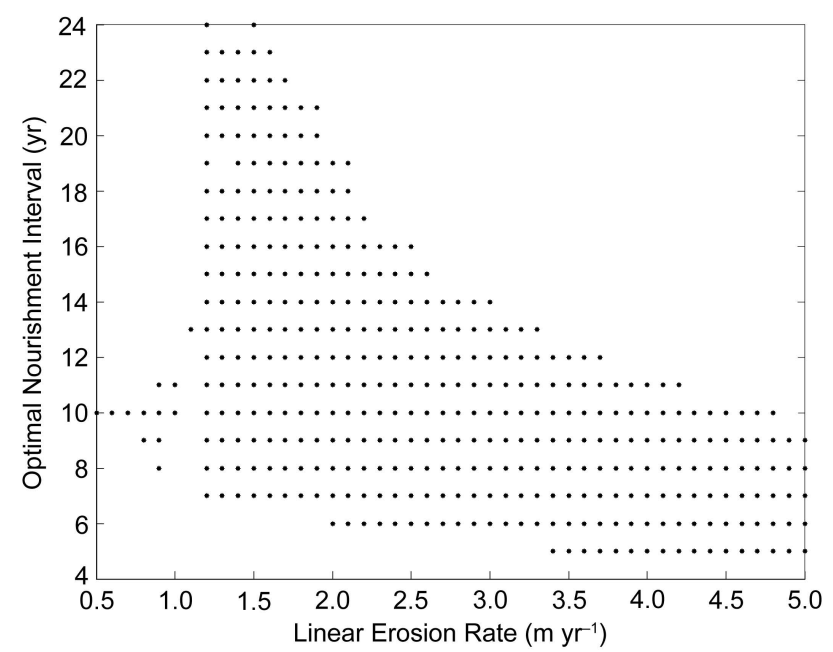

Fig. 6. Bifurcation-type plot summarizing nourishment-interval choices $(\tau)$ by 100 model towns over 1000 time steps for a range of linear erosion rates $\left(\gamma_{\mathrm{r}}\right)$. A critical transition from single-state to a "chaotic" pattern of multiple states occurs at $\gamma_{\mathrm{r}}=1.2 \mathrm{~m} \mathrm{yr}^{-1}$.

details of the resulting patterns, but the dynamics represented in the patterns remain the same.

Perturbing the system economically can also destabilize shoreline behavior. Though we do not present the results here, we experimented with a variety of economic-parameter settings. For example, randomly introducing "wealthy" towns with an elevated property value $(\alpha)$ into a domain of non-wealthy towns perturbs shoreline behavior because $\tau$ choices available to manager agents of wealthy and nonwealthy towns derive from different parameter spaces. Increasing the property value $(\alpha)$ shortens optimal nourishment intervals; the steep gradient that dominates the SW quadrant of Fig. 1 shifts down and off the parameter space, giving way to the shorter nourishment intervals and widely spaced contours that comprise the comparatively flat NW quadrant. The economic argument for this shift is that wealthy towns tend to nourish their beaches more frequently because the marginal benefits (which depend on base property values) from a wide beach are higher (Smith et al., 2009).

\subsection{Diffusivity and time scales of attractors}

Adjusting the diffusion constant $K$ by an order of magnitude higher or lower affects how rapidly the domain settles into an attractor. At low values of $K$, little sediment is shared across towns and the domain finds the attractors quickly. Alternatively, when $K$ is high, so much sand is distributed across towns that manager agents' interpretations of beach behavior tend to be inaccurate, and the domain takes longer to find the attractors. Our upper-bound for the diffusion constant is analogous to the high-energy environment of the US West Coast, and the lower-bound is arguably more typical of the 
low-energy environment of the US Gulf Coast. Intermediate values of $K$ used here are comparable to the diffusivity of the US Eastern Seaboard (e.g. Ashton and Murray, 2006b).

\subsection{Caveats}

Our beach-dynamics model does not explicitly incorporate a number of characteristics and processes that are important to real coastlines, such as wave refraction over hydrography near the shore or storm events. Nevertheless, exponential cross-shore relaxation of the beach profile $(\theta)$ and lateral diffusion of sand are behaviors that capture shoreline dynamics relevant at large spatial scales (Dette et al., 1994; Dean, 2002; Falqués and Calvete, 2005; Lazarus et al., 2011).

Likewise, we keep several physical parameters constant, including $x_{0}$, the full ("maximum") width to which a beach is nourished, and $\mu$, the fraction of the maximum beach width that erodes exponentially. In reality, the width to which a beach is nourished depends on a host of project-specific circumstances - the price of sand, the availability of equipment, the source of funding for the project, et cetera. That said, the fixed costs of beach nourishment (hiring a dredge, acquiring a permit, marshalling materials) are high enough to force economies of scale - a large nourishment project is generally more cost effective than a small one (e.g. Smith et al., 2009). Though outside the scope of this model, related work does consider dynamic economic elements such as variable costs driven by a competitive market for sand (McNamara and Werner, 2008a; McNamara et al., 2011).

\subsection{Collectively undershooting the economic optimum}

The possibility of even weakly chaotic behavior among neighboring beach towns carries sobering implications for management strategies. The rates of linear erosion we explore in our model are within the range of plausible environmental conditions: Along the low-lying coast of North Carolina, for example, 50-yr average beach erosion rates (excluding inlets) range from $<0.5 \mathrm{~m}$ to $>4 \mathrm{~m} \mathrm{yr}^{-1}$ (NC DCM, 2010), which future sea-level rise will only tend to exacerbate.

Optimizing net benefits assumes fundamentally that the optimization calculation, which projects forward into infinite time (Eq. 7), occurs only once (e.g. Fig. 2a). A town with perfect information about its physical coastal conditions should determine a single optimal interval over which to nourish its beach for the rest of time. But when placed in even a highly stylized physical setting in which sand is shared among neighboring towns by diffusion, a given town's information about shoreline conditions becomes imperfect. The frequently changing conditions that occur in a chaotic regime require that towns adjust and readjust their calculated nourishment intervals. By extension, no town can act in a truly economically optimal way by using a spatially myopic decision-making process. Towns that wait out long intervals between nourishment events, as they do when caught in a checkerboard pattern (Fig. 4), will tend to have narrower mean beach widths with lower associated economic benefits (Smith et al., 2009). As towns search independently for what is economically optimal, spatially myopic management in a context of diffusion and high erosion rates affects a collective decrease in net benefits for all towns in the domain.

This systemic undershooting of the optimum is similar to problems encountered in the context of spatially incompatible land-use practices (Parker, 1999). A case study of organic and non-organic farms in the Central Valley of California by Parker and Monroe (2007) describes the spatial impact that non-organic farms have on their organic neighbors. Because non-organic farms use chemical fertilizers and pesticides as part of their farming practices, neighboring organic farms must ensure that a buffering strip of fallow land separates the two kinds of fields to maintain organic certifiability. This impinging partition is termed an "edge-effect externality", a spatial phenomenon defined by a marginal impact that is inversely related to the distance from the border generating the externality (Parker, 1999). A geometric thought experiment demonstrates that spatially heterogeneous arrangements of organic and non-organic farms that minimize incompatible borders thereby maximize the amount of arable land in production. Realizing a maximally beneficial arrangement, however, requires some measure of cooperation among farmers in the system, and not a simple reliance on "free market land use patterns" (Parker and Munroe, 2007).

The initial instability and two-state pattern in our beachnourishment model (Figs. 2c and 4) could be described as a "propagating" edge-effect externality. Groups of towns that nourish in unison locally increase their compatible borders and thereby approach the gains suggested by the optimal scenario, in which all towns nourish in unison for all time (Fig. 2a). The consequence of independent operation is that when a few towns do nourish as a coherent group, those towns at the edges experience higher rates of erosion and so must change their nourishment strategies, ultimately paring down the group size and pushing the possibility of collective economic optimum farther away.

We do not presume that coastal managers of real towns measure linear versus exponential erosion on their beaches and then literally calculate a target nourishment interval, or that beach-nourishment projects reflect the unilateral decisions of a particular person. Even so, the economic model by Smith et al. (2009) that guides manager-agent behavior in our coupled model is not an esoteric abstraction. Beachnourishment records (PSDS, 2010) and discussions with coastal town managers (A. Coburn, PSDS, personal communication, 2008) suggest a lack of nourishment coordination between neighboring towns is typical, currently and historically. Some nourishment projects are implemented as emergency responses to storm events (PSDS, 2010), and some managers may be aware of larger scale, multi-town patterns over time - but if strategic behavior has arisen from 
perception of those spatial patterns, it has either not persisted or is simply not apparent in the records. Though expressed in parameters that do not fully represent the nuances of reality, the spatial myopia underpinning the model by Smith et al. (2009) captures the salient dynamics of real municipalities trying to manage coastal erosion (e.g. Psuty and Ofiara, 2002).

Less myopic interactions among managers could produce different results. Recent evidence suggests beachnourishment strategies in some areas of the US are moving, however tentatively, from independent actions toward more cooperative management arrangements. On the southern North Carolina coast, a board of town commissioners for the developed barrier island of Bogue Banks, which consists of five communities spanning approximately $40 \mathrm{~km}$ of beach frontage, recently approved a preliminary pact that would place the entire island under a single, comprehensive, 30-yr "master beach nourishment plan" (Kemp, 2010). Opposition to the plan hinges on its costs and concerns regarding entangled obligations to other municipalities (Kemp, 2010); the outcome of the proposed cooperation remains to be seen.

\subsection{Broader insights}

Though manager-agent behavior in this model is driven by the parameter relationships illustrated in Fig. 1, the emergent patterns that our model produces suggest some broader lessons regarding coupled human-landscape systems. Fundamentally, an optimal nourishment interval is a quantity informed by properties of a physical environment that corresponds to a certain kind of management action. In more general terms, the parameter space in Fig. 1 could be called a "decision space". Our results illustrate, in a way obliquely related to Feigenbaum (1978), that a decision space characterized by steep gradients, wherein small differences in environmental parameters can result in widely differing management behavior, can result in highly disorganized, even chaotic coupled-system behavior. When management decisions are less sensitive to environmental parameters (gradients in the decision space are shallow), the coupled system may be more likely to lock into a simple attractor.

\subsection{Future directions}

Records of beach-nourishment projects up and down the US seaboards exist (e.g. PSDS, 2010), but multi-decadal timeframes are exceptional cases, complicating comparison of our simulations to empirical evidence. The fact that longterm nourishment projects are codified by multi-decadal permits suggests that our dynamical predictions might take several more decades to play out, unless environmental factors accelerate systemic behavior. Further explorations of this coastal setting already underway will introduce additional layers of dynamic physical influences, such as shoreline orientation and a variable wave environment (e.g. Ashton et al., 2001), as well as address higher-order economic questions set aside in this discussion, such as how wealth disparities among neighboring municipalities affect competition for limited sand resources (McNamara et al., 2011) and the implications of strategic interactions in neighboring nourishing communities.

\section{Conclusion}

Our model of a coupled economic-beach system demonstrates a chaotic threshold and the emergence of new attractors with changes in external forcing. When town-scale, spatially myopic beach management occurs in a spatially extended setting shared by multiple towns, one town's beach conditions (and resulting management actions) become a function of the management actions taken by its neighbors.

Acknowledgements. This work was made possible by National Science Foundation awards DEB-0507987, EAR-0952120, EAR-0951802, and EPS-0904155. E. Lazarus would also like to thank Andrew Pershing, and the Visiting Scientist program at the Gulf of Maine Research Institute.

Edited by: U. Feudel

Reviewed by: two anonymous referees

\section{References}

Abarbanel, H. D. I.: Analysis of Observed Chaotic Data, Institute for Nonlinear Science, Springer, New York, 1986.

Albers, H. J., Ando, A. W., and Batz, M.: Patterns of multi-agent land conservation: Crowding in/out, agglomeration, and policy, Resour. Energy Econ., 30, 492-508, 2008.

Ashton, A., Murray, A. B., and Arnoult, O.: Formation of coastline features by large-scale instabilities induced by high-angle waves, Nature, 414, 296-300, 2001.

Ashton, A. D. and Murray, A. B.: High-angle wave instability and emergent shoreline shapes: 1. Modeling of sand waves, flying spits, and capes, J. Geophys. Res., 111, F04011, doi:10.1029/2005JF000422, 2006a.

Ashton, A. D. and Murray, A. B.: High-angle wave instability and emergent shoreline shapes: 2 . Wave climate analysis and comparisons to nature, J. Geophys. Res., 111, F04012, doi:10.1029/2005JF000423, 2006b.

Bell, K. P. and Irwin, E. G.: Spatially explicit micro-level modeling of land use change at the rural-urban interface, Agr. Econ., 27, 217-232, 2002.

Casdagli, M.: Nonlinear prediction of chaotic time series, PhysicaD, 35, 335-356, 1989.

Dean, R. G.: Beach nourishment: Theory and practice, World Scientific, Hackensack, N. J., 2002.

Dean, R. G. and Dalrymple, R. A.: Coastal processes with engineering applications, Cambridge University Press, Cambridge, United Kingdom, 2002.

Dette, H. H., Führböter, A., and Raudkivi, A. J.: Interdependence of beach fill volumes and repetition intervals, J. Waterw. Port CASCE, 120, 580-593, 1994. 
Edwards, S. F. and Gable, F. J.: Estimating the value of beach recreation from property values: An exploration with comparisons to nourishment costs, Ocean and Shoreline Management, 15, 3755, 1991.

Falqués, A., and D. Calvete: Large-scale dynamics of sandy coastlines: Diffusivity and instability, J. Geophys. Res., 110, C03007, doi:10.1029/2004JC002587, 2005.

Feigenbaum, M. J.: Quantitative universality for a class of nonlinear transformations, J. Stat. Phys., 19, 25-52, 1978.

Gopalakrishnan, S., Smith, M. D., Slott, J. M., and Murray, A. B.: The value of disappearing beaches: A hedonic pricing model with endogenous beach width, J. Environ. Econ. Manag., 61, 297-310, 2011.

Irwin, E. G. and Bockstael, N. E.: Interacting agents, spatial externalities, and the evolution of residential land use patterns, J. Econ. Geogr., 78, 465-481, 2002.

Kemp, S.: Pine Knoll Shores joins beach pact, Carteret News-Times, 12 March 2010: available at: http: //www.carteretnewstimes.com/articles/2010/03/13/news-times/ news/doc4b9a80728d088578537281.txt, last access: May 2011.

Kreisel, W., Landry, C. and Keeler, A.: Coastal erosion management from a community economics perspective: The feasibility and efficiency of user fees, J. Agr. Appl. Eco., 37, 45-461, 2005.

Landry, C. E., Keeler, A. and Kriesel, W.: An economic evaluation of beach erosion management alternatives, Mar. Resour. Econ., 18, 105-127, 2003.

Lazarus, E., Ashton, A., Murray, A. B., Tebbens, S., and Burroughs, S.: Cumulative versus transient shoreline change: Dependencies on temporal and spatial scale, J. Geophys. Res., 116, F02014, doi:10.1029/2010JF001835, 2011.

McNamara, D. E. and Werner, B. T.: Coupled barrier islandresort model: 1. Emergent instabilities induced by strong human-landscape interactions, J. Geophys. Res., 113, F01016, doi:10.1029/2007JF000840, 2008a.

McNamara, D. E. and Werner, B. T.: Coupled barrier islandresort model: 2 . Tests and predictions along Ocean City and Assateague Island National Seashore, Maryland, J. Geophys. Res., 113, F01017, doi:10.1029/2007JF000841, 2008b.

McNamara, D. E., Murray, A. B., and Smith, M. D.: Coastal sustainability depends on how economic and coastline responses to climate affect each other, Geophys. Res. Lett., 38, L07401, doi:10.1029/2011GL047207, 2011.

NC DCM: Long-term average annual erosion study, Division of Coastal Management, North Carolina Department of Environment and Natural Resources: available at: http://dcm2.enr.state. nc.us/Maps/SB_Factor.htm, last access: September 2010.

NOAA: Beach Nourishment: A Guide for Local Government Of?cials, NOAA Coastal Services Center, 2006.

NRC: Beach nourishment and protection (executive summary), Marine Board, Commission on Engineering and Technical Systems, National Research Council, National Academy Press, Washington, DC, USA, 1995.

Parker, D.: Landscape outcomes in a model of edge-effect externalities: A computational economics approach, Santa Fe Institute working paper \#99-07-051, Santa Fe, NM, USA, 1999.
Parker, D. C. and Munroe, D. K.: The geography of market failure: Edge-effect externalities and the location and production patterns of organic farming, Ecol. Econ., 60, 821-833, 2007.

Parker, D. C., Manson, S. M., Janssen, M. A., Hoffman, M. J., and Deadman, P.: Multi-agent systems for the simulation of land-use and land-cover change: a review, Ann. Assoc. Am. Geogr., 93, 314-37, 2003.

Parsons, G. R. and Powell, M.: Measuring the cost of beach retreat, Coast. Manage., 29, 91-103, 2001.

Pilkey, O. H. and Dixon, K. L.: The Corps and the Shore, Island Press, Washington, DC, USA, 1996.

Pilkey, O. H. and Wright III, H. L.: Seawalls versus beaches, J. Coast. Res., SI 4, 41-64, 1988.

Pompe, J. J. and Rinehart, J. R.: Beach quality and the enhancement of recreational property values, J. Leisure Res., 27, 143154, 1995.

PSDS: Beach nourishment database, Program for the Study of Developed Shorelines, available at: http://www.wcu.edu/1038.asp, last access: August 2010.

Psuty, N. P. and Ofiara, D. D.: Coastal hazard management, Rutgers Univ. Press, Newark, NJ, 2002.

Rosen, S.: Hedonic prices and implicit markets: Product differentiation in pure competition, J. Polit. Econ., 82, 34-55, 1974.

Sanchirico, J. N. and Wilen, J. E.: Optimal spatial management of renewable resources: Matching policy scope to ecosystem scale, J. Eviron. Econ. Manag., 50, 23-46, 2005.

Smith, M. D., Slott, J. M., McNamara, D., and Murray, A. B.: Beach nourishment as a dynamic capital accumulation problem, J. Environ. Econ. Manag., 58, 58-71, 2009.

Sornette, D.: Critical phenomena in natural sciences, 2nd Edn., Springer-Verlag Berlin Heidelberg, Germany, 2006.

Sugihara, G. and May, R.: Nonlinear forecasting as a way of distinguishing chaos from measurement error in time series, Nature, 344, 734-741, 1990.

Sugiyama, M.: Estimating the economic cost of sea-level rise, M.S. thesis, Massachusetts Institute of Technology, Cambridge, Massachusetts, USA, 2007.

Swallow, S. K., Talukdar, P., and Wear, D. N.: Spatial and temporal specialization in forest ecosystem management under sole ownership, Am. J. Agr. Econ., 79, 311-326, 1997.

Titus, J. G., Park, R. A., Leatherman, S. P., Weggel, J. R., Greene, M. S., Mausel, P. W., Brown, S., Gaunt, G., Trehan, M., and Yohe, G.: Greenhouse effect and sea-level rise: The cost of holding back the sea, Coast. Manage., 19, 171-204, 1991.

Werner, B. T. and McNamara, D. E.: Dynamics of coupled humanlandscape systems, Geomorphology, 91, 393-407, 2007.

Wilson, J. A.: Matching social and ecological systems in complex ocean fisheries, Ecol. Soc., 11(1), 9, available at: http://www. ecologyandsociety.org/vol11/iss1/art9/, 2006.

Wilson, J. A., Yan, L. and Wilson, C.: The precursors of governance in the Maine lobster fishery, P. Natl. Acad. Sci. USA, 104, 39, doi:10.1073/pnas.0702241104, 2007.

Wolinsky, M. A. and Murray, A. B.: A unifying framework for shoreline migration: 2. Application to wave-dominated coasts, J. Geophys. Res., 114, F01009, doi:10.1029/2007JF000856, 2009. 